\title{
Adjuvant low-intensity photodynamic procedures in periodontal treatment: A case series report from dental practice
}

\author{
Michel Vock ${ }^{1}$, Corinna Rigassi-Vock ${ }^{1}$, Claudia Dehn ${ }^{2}$, Matthias Frentzen² and Jörg Meister ${ }^{3,4 *}$ \\ ${ }^{1}$ Praxisteam Seuzach, Turnerstrasse 22, 8472 Seuzach, Switzerland \\ ${ }^{2}$ Department of Operative and Preventive Dentistry, Bonn University, Welschnonnenstrasse 17, 53111 Bonn, Germany. \\ ${ }^{3}$ Center of Dento-Maxillo-Facial Medicine, Bonn University, Welschnonnenstrasse 17, 53111 Bonn, Germany \\ ${ }^{4}$ Center of Applied Medical Laser Research and Biomedical Optics (AMLaReBO), Bonn University, Welschnonnenstrasse 17, 53111 Bonn, Germany
}

\begin{abstract}
The steady progression of antibiotic resistances results in calls for alternative therapeutic options such as the adjuvant antimicrobial photodynamic therapy. The objective of this case series study was to mutually compare different photodynamic procedures in periodontal treatment.

10 patients with chronic periodontitis were treated with different photodynamic procedures in 3 quadrants after scaling and root planing. Two photodynamic procedures (gingival pocket and transgingival irradiation) and a low-intensity laser therapy (LILT) were applied. The parameters Plaque index, Bleeding on probing, Probing depth and a microbiological marker test were recorded in all quadrants at the baseline and after 3 and 6 months.

A significant reduction in the Plaque index $(p<0.001)$ was achieved in all test groups over the entire treatment period. Regarding the Probing depth, a reduction was also observed for all procedures, relative to the baseline, but no differences between the individual procedures could be found. For Bleeding on probing, a statistically significant reduction was observed after 3 months for aPDT-gingival pocket irradiation $(p=0.038)$. Comparison of the different therapy groups in terms of the total pathogen bacteria count revealed a reduction after the defined periods. After three months, trends regarding bacteria count reduction were observed, but not be proven statistically. After six months, for gingival pocket irradiation a statistical significant bacteria reduction was verifiable $(p=0.022)$.
\end{abstract}

\section{Introduction}

As a result of demographic change, there is rapid growth of the cohorts of elderly and aged patients who still have their natural teeth, especially in the industrialised nations. These patients often also receive multimedication owing to age-related, systemic illnesses, these inducing a range of side-effects [1]. This is compounded by the steady progression of antibiotic resistances in recent years [2,3]. Based on this trend, there is a call to reduce the necessary administration of antibiotics to the greatest possible extent. This particularly applies to the treatment of chronic diseases, such as periodontitis, which necessitate frequently repeated doses of antibiotics in the framework of anti-infectious therapy on the basis of general medical and dental indications [4].

Mechanical surface treatment (Deep Scaling and Root Planing, SRP) and the resultant removal of the supragingival and subgingival biofilm is considered to be the "gold standard" in periodontal treatment. The objective of this procedure is to destroy the bacterial biofilm, reduce bacterial colonization and retard recontamination of the periodontal lesion [5,6]. Antibiotic treatment has frequently been documented as an adjunctive aid for eliminating microbial colonization in the literature [7-9]. However, the literature bears witness to the numerous side-effects and the danger of resistances developing following the systemic intake of antibiotics [10,11]. It is for this reason that photonic, adjuvant therapeutic procedures for the elimination of periopathogenic bacteria were developed.
Photodynamic therapy (PDT), a minimally invasive method from oncology has been further developed into antimicrobial photodynamic therapy (aPDT), a non-invasive form of treatment with the aim of bacterial reduction [12-15]. The mode of action is based on lightinduced inactivation of cells, microorganisms or molecules, which were preferably marked by means of artificial chromophores, known as photosensitizers. This form of treatment generally displays no side-effects and development of resistances whatsoever. Numerous studies demonstrate the efficacy of PDT/aPDT in the treatment of periodontitis and periimplantitis [16-24]. This effective elimination of periopathogenic bacteria by aPDT such as Streptococcus sangius, Fusobacterium nucleatum, Porphyromonas gingivalis and Aggregatibacter actinomycetemcomitans was documented by in-vitro studies [25-27].

Both aPDT (incl. photosensitizer) and low-intensity laser therapy (LILT, without photosensitizer) are used as adjuvant treatment to supplement classical periodontal therapy. The scientific results show

*Correspondence to: Jörg Meister, Center of Dento-Maxillo-Facial Medicine, Bonn University, Welschnonnenstrasse 17, 53111 Bonn, Germany, Tel: +49 228 287 22268; Fax: +49 228287 22694; E-mail: jmeister@uni-bonn.de

Key words: periodontitis, antimicrobial photodynamic therapy (apdt), low intensity laser therapy (lilt), gingival pocket irradiation, transgingival irradiation

Received: September 25, 2019; Accepted: October 03, 2019; Published: October 07,2019 
that aPDT may be a promising alternative to the previously applied systemic administration of antibiotics [28-30].

aPDT is currently applied in two different ways: both gingival pocket irradiation and transgingival irradiation. In the gingival pocket version, a light guide is inserted into the periodontal pocket (much like a periodontal probe), the photosensitizer thus being activated directly in the pocket by means of laser light. A light guide with a diameter of approximately $8 \mathrm{~mm}$ is used for transgingival irradiation. In this case, light activation of the photosensitizer is carried out by external irradiation of the gingiva, where light or energy transfer takes place through the tissue into the pocket. Both systems were previously investigated scientifically, but they have never yet been compared.

Alternative methods in dentistry, especially in periodontology, were investigated in order to improve the treatment outcome after periodontally therapeutic interventions, for example, electrostimulation, magnetic fields, heat, hyperbaric oxygen or local oxygen therapy and low-intensity laser therapy [31].

Low-intensity laser therapy (also referred to as low-level laser therapy or biomodulation or biostimulation in the literature), requires an optimum dose of laser light for application (therapeutic window given by the Arndt-Schultz-law). Visible and near-infrared light are the wavelengths customarily used. The mode of action of LILT is currently still the subject of numerous scientific investigations, since it has not yet been possible to completely describe the precise action process $[32,33]$. Nevertheless, CASTro, et al. [34] were able to demonstrate that a therapeutic combination of SRP and LILT achieved better results than SRP alone. Moreover, KREISLER, et al. [35] reported that the application of LILT encourages the biostimulation process and accelerates the healing process. In general terms, LILT has a positive effect on the fibroblasts of the periodontal ligament and fibroblasts of the gingiva and brings about a supportive effect on periodontal healing [36-38]. Compared to classical SRP without laser application, the TGF- $\beta 1$ level is distinctly reduced by the adjuvant treatment in the event of SRP with LILT $[39,40]$. In addition, the periodontal pocket depth (PPD) and clinical attachment loss (CAL) are reduced to a significantly greater extent than in the control group without LILT [41]. In general, the literature shows that the use of adjuvant LILT has a positive effect on the healing process within the scope of periodontal therapy [42].

No direct comparison of all the different low-intensity photodynamic procedures mentioned above is to be found in the literature. Therefore, the aim of this clinical trial was the direct comparison of these procedures in dental practice.

\section{Material and methods}

\section{Ethical approval}

Patients signed a consent agreement after receiving information on the purposes, design and data management of this recall study. This study was conducted in accordance with the principles of the Declaration of Helsinki, the Swiss Dental Association (SSO) and in line with the regulations of the German Act on Medical Products (MPG).

\section{Test subjects}

In total, 10 volunteers were selected for this practical trial. The patient distribution was as follows: 5 female and 5 male subjects with an average age of 56.7 and 50.4 years were selected. 7 of them were smokers (including all the female participants) and 3 non-smokers $[23,43]$. All patients presented chronic periodontitis.
The inclusion and exclusion criteria were specified as follows:

- no previously treated periodontitis (SRP or antibiosis) before the clinical trial starts

- no systematic antibiotic therapy in the 12 months before the clinical trial starts

- no pregnancy

- no allergies regarding photosensitizer substances

- at least 4 teeth per quadrant having pocket depths $\geq 5 \mathrm{~mm}$

\section{Photodynamic systems}

Two different systems were used in the context of antimicrobial photodynamic therapy (aPDT), for gingival pocket irradiation and transgingival irradiation. In addition, pure low-intensity laser therapy (LILT) was used in transgingival application. The therapeutic laser systems for photodynamic therapy are listed in Table 1.

The HELBO TheraLite system (Bredent Medical GmbH \& Co KG, Walldorf, Germany) was used in CW-mode with an output power of $40 \mathrm{~mW}$. For optimized handling inside the pocket, the distal end of the HELBO 3D Pocket Probe is bent approx. $45^{\circ}$ relative to the optical axis of the laser source. Laser light distribution of $360^{\circ}$ perpendicular to the probe axis was realized by a special design of the probe material.

The ORCOS Medical MED-701 system (ORCOS Medical AG, Küssnacht, Switzerland) was always used in CW-mode, but with two different power settings, depending on whether aPDT or LILT treatment was used. The output powers were $305 \mathrm{~mW}$ for aPDT and $420 \mathrm{~mW}$ for LILT, measured at the distal end of the light guide.

\section{Clinical procedures}

Prior to the start of treatment, all participants were informed about the individual steps of the therapeutic measures, both verbally and in writing. The treating physician was assured of the informed consent regarding participation in this case series.

At baseline (BL), the periodontal status was documented with the help of the Florida probe (Florida Probe Corporation, Gainesville, $F L, U S A)$. The parameters recorded included the plaque index (PI), the occurrence of bleeding on probing (BoP), and the probing depth (PD). Additionally performed was a microbiological marker test for the bacteria Actinobacillus actinomycetemcomitans (Aggregatibacter actinomycetemcomitans) Aa, Bacteriodes forsythus (Tannerella forsythia) $\mathrm{Bf}$, Porphyromonas gingivalis Pg and Treponema denticola Td by means of RNA hybridization (IAI-PadoTest 4.5, Institut für Angewandte Immunologie IAI AG, Zuchwil, Switzerland) in four periodontal pockets with the greatest probing depths per quadrant and per patient.

Table 1. Overview of laser systems used for photodynamic therapy

\begin{tabular}{|c|c|c|c|}
\hline Treatment & Laser & Photosensitizer & Applicator \\
\hline $\begin{array}{c}\text { aPDT (1) } \\
\text { (gingival pocket } \\
\text { irradition) }\end{array}$ & $\begin{array}{c}\text { HELBO } \\
\text { TheraLite }(660 \mathrm{~nm})\end{array}$ & HELBO Blue* & $\begin{array}{c}\text { HELBO } \\
\text { 3D Pocket Probe }\end{array}$ \\
\hline $\begin{array}{c}\text { aPDT (2) } \\
\text { (transgingival } \\
\text { irradiation) }\end{array}$ & $\begin{array}{c}\text { ORCOS Medical } \\
\text { MED-701 (670 nm) } \\
\text { (SN: } 11036)\end{array}$ & $\begin{array}{c}\text { Methylene blue } \\
\text { solution ** }\end{array}$ & $\begin{array}{c}\text { bended lightguide } \\
\varnothing=8 \text { mm @ distal } \\
\text { end }\end{array}$ \\
\hline $\begin{array}{c}\text { LILT } \\
\text { (transgingival } \\
\text { irradiation) }\end{array}$ & $\begin{array}{c}\text { ORCOS Medical } \\
\text { MED-701 }(808 \mathrm{~nm}) \\
\text { (SN: } 11023)\end{array}$ & no photosensitizer & $\begin{array}{c}\varnothing=8 \mathrm{~mm} @ \text { m distal } \\
\text { end }\end{array}$ \\
\hline
\end{tabular}

*Phenothiazine chloride (a thiazine derivative buffered to a $\mathrm{pH}$ value of 3.5 using a citrate buffer system, isotoic with $1 \%$ HPMC, optimized concerning to its viscosity).

$* * 1 \%$ buffered, produced by pharmacy. 
Classical scaling and root planing (SRP) of all quadrants was performed in a single sitting, under local anaesthesia and by means of an ultrasonic scaler (Satelec Suprasson Newtron (applicator 10Z)) as basic therapy for treating the chronic periodontitis. This was defined as the control group $(\mathrm{C})$. The adjuvant laser-assisted therapeutic measures (aPDT (1), aPDT (2), LILT) were performed on each patient the same day, distributed evenly over the four quadrants, and likewise during the one sitting. The distribution was randomized within limits, since the two aPDT-measures (aPDT (1) and aPDT (2)) were not performed simultaneously in adjacent quadrants of a jaw.

The consultation ended with instructions on oral hygiene, which were to be observed by the patient during the control phase. In addition, professional dental cleaning, (supragingival debridement), including instructions on oral hygiene, was performed by a dental hygienist, over the periods 1 week post, 1 month post and 2 months post treatment.

\section{Laser treatment}

For aPDT (both gingival pocket irradiation, aPDT (1) and transgingival irradiation, aPDT (2)), the photosensitizer was applied to all teeth in the respectively selected quadrants. In compliance with the manufacturer's instructions, the exposure time was 2 minutes. The surplus photosensitizer was subsequently removed ultrasonically. Laser irradiation during aPDT (1) was performed at 6 positions on the tooth (mesio-buccal, buccal, disto-buccal, disto-oral, oral and mesio-oral) for 20 seconds in each instance, in accordance with the manufacturer's instructions. During aPDT (2), irradiation of the pocket was performed from buccal and oral for 1 minute, likewise in accordance with the manufacturer's instructions. The applicator used for this purpose (Table 1) was moved from mesial to distal in contact with the gingiva, in order to optimally illuminate the fundus. The total dose applied per tooth was $72.76 \mathrm{~J} / \mathrm{cm}^{2}$.

LILT (Table 1) was performed similarly to aPDT (2), except that the irradiation time was increased to 2 minutes, this resulting in an increase in the applied dose per tooth to $110.2 \mathrm{~J} / \mathrm{cm}^{2}$.

The periodontal status was re-evaluated after 3 and 6 months, by again recording the plaque index (PI), bleeding on probing (BoP), the probing depth (PD) and the IAI Test.

\section{Statistical evaluation}

After entering the data in a spreadsheet program (Microsoft Excel, Redmond, USA), statistical evaluation was performed using the statistics software IBM SPSS Statistics, Version 22 (IBM, New York, USA). Because a Gaussian distribution could not be assumed, a nonparametric test method for related samples was used (Wilcoxon test). Statistically significant differences were defined by the significance level $\alpha \leq 0.05$. The different treatment methods (SRP, SRP \& aPDT (1), SRP \& aPDT (2) and SRP \& LILT) were compared for the investigated parameters (BoP, PD and microbiological marker test) at the individual investigation times (baseline, three months and six months). This made it possible to record the differences between the individual treatment groups and within the respective treatment groups at the individual investigation times (therapeutic relevance).

\section{Results}

No adverse side effects occurred throughout the entire observation period in the framework of the clinical application of the different therapeutic measures. Owing to the fact that scaling and root planning was performed in all quadrants prior to each adjuvant therapeutic measure (aPDT (1) \& (2) and LILT), all patients showed a clinical improvement of their periodontal status in terms of PI, BoP and PD (Figures 1-3) after 3 and 6 months.

\section{Plaque Index (PI)}

The Plaque index remained at the same level in all the quadrants recorded at the individual examination times ( 3 and 6 months). The instructions and care given to the patients made it possible to achieve a distinct reduction, compared to the baseline $(p<0.001$, Figure 1$)$.

\section{Bleeding on Probing (BoP)}

Generally speaking, and in relation to the baseline, statistically significant reductions in $\mathrm{BoP}(p \leq 0.009)$ were demonstrated after 3 and 6 months (Figure 2). Mutual comparison of the baseline values (BL) revealed no statistically significant difference.

Compared to the control group, no significant differences can be found for the treatment periods of 3 and 6 months for transgingival

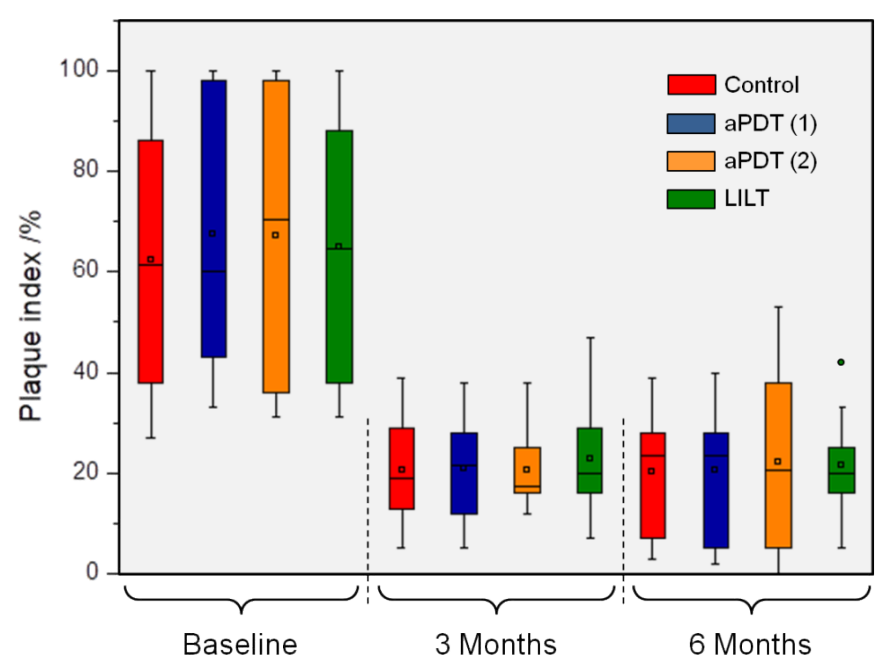

Figure 1. Plaque index shown at baseline and at the individual examination times ( 3 and 6 months). A statistical significant reduction compared to the baseline could be recorded in all cases $(p<0.001)$

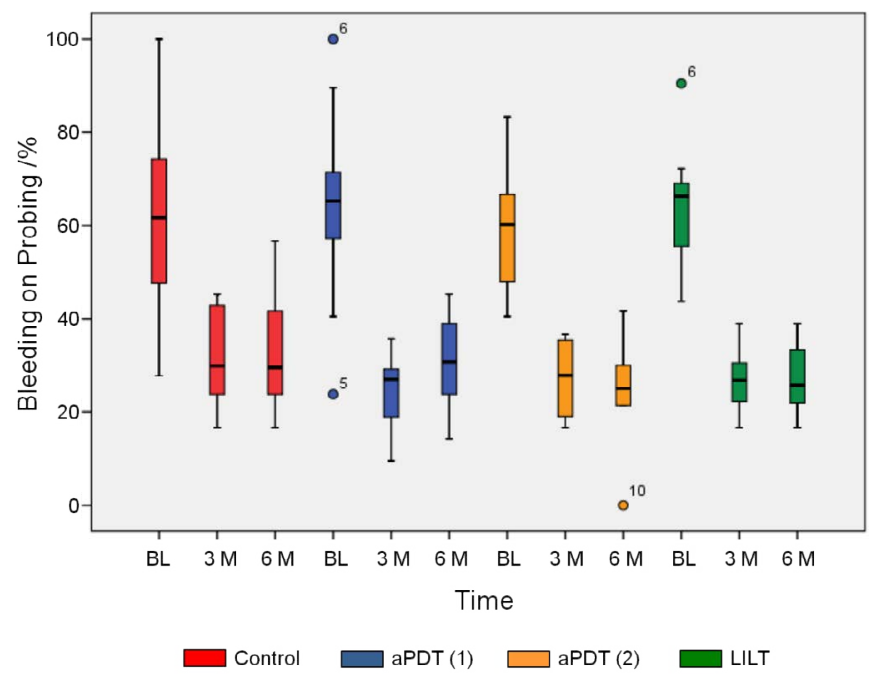

Figure 2. Bleeding on probing shows generally a statistical significant reduction in all tes groups after 3 and 6 months $(p \leq 0.009)$ compared to baseline (BL). Only for aPDT (1) a statistical significant reduction compared to the control group could be observed $(p=0.038)$ 
irradiation (aPDT (2)) and low-intensity laser therapy (LILT). These therapeutic procedures also revealed no differences after 3 and 6 months in the course of the monitoring phase.

Gingival pocket irradiation (aPDT (1)) was capable for achieving a statistically significant reduction for the first study period ( 3 months), compared to the control group ( $p=0.038$ ). This effect was, however, no longer detectable after 6 months.

\section{Probing Depth (PD)}

As an indicator for the therapeutic effect, a reduction in the probing depth was found in all test groups in the framework of the monitoring phase (Figure 3). No differences could be detected between the test groups.

\section{Microbiological marker test}

Figure 4 shows a survey of the overall response of all the investigated bacteria after implementation of the therapeutic measures. Comparison of the different quadrants at baseline, each of which can be assigned to a treatment protocol, reveals no significant differences. As was generally to be expected, all treatments resulted in a reduced germ count after the defined periods ( 3 and 6 months). After three months, there were signs of trends regarding the germ count reduction (medians), but they could not be proven statistically. These trends increased after 6 months, in that statistically significant germ count reduction was demonstrated, compared to the control group, for aPDT (1) with a $p$-value of 0.022 . These trends likewise increased for the measures aPDT (2) and LILT, with $p_{a P D T(2)}=0.059$ and $p_{L I L T}=0.114$, although no corresponding significance level was reached.

This response is clearly illustrated by the analyses of the individual bacteria Aa, Bf, Pg and Td (Figures 5a-5d).

Detection at baseline was already borderline for the germ Aggregatibacter actinomycetemcomitans (Aa). After the therapeutic measures, the values for both investigation periods were below the detection limit (Figure 5a). Germ reductions for Tannerella forsythia (Bf) were likewise determined for both investigation periods. However, only after three months was it possible to demonstrate a significant difference between the control group and the aPDT (1) group, in favour of the control group, with a $p$-value of 0.038 (Figure 5b).

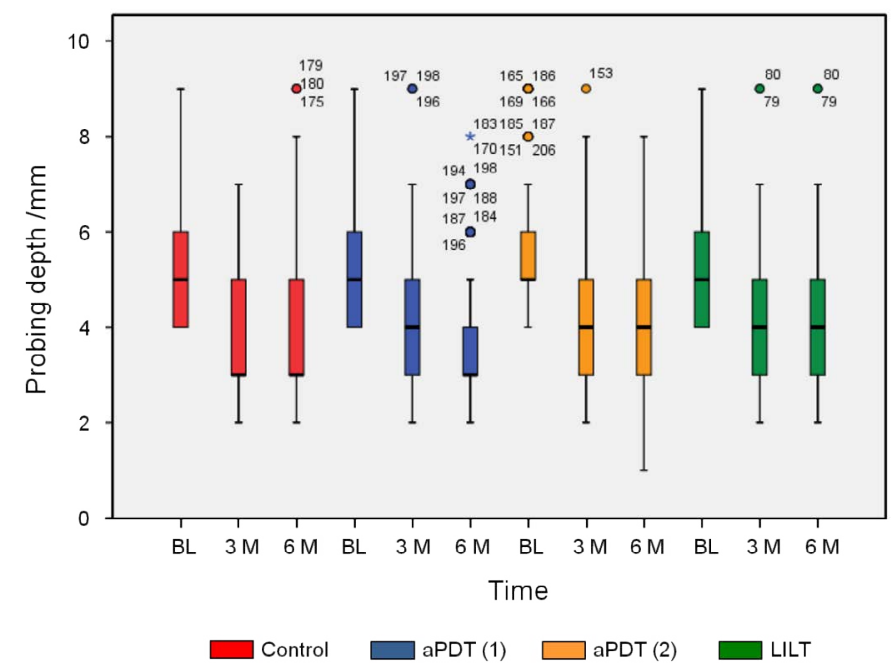

Figure 3. Probing depth as an indicator for the therapeutic effect. Scaling and root planing as well as the different laser therapies show a reduction in the probing depth (BL: Baseline, M: Months)

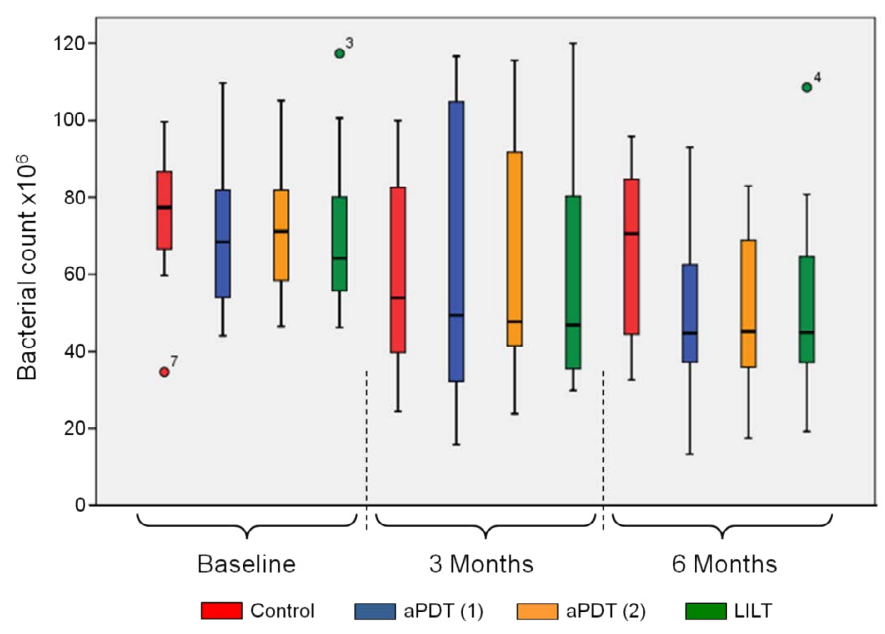

Figure 4. Overview of the overall response of all the investigated germs at baseline as well as after 3 and 6 months, dependent of the different laser therapies applied

Porphyromonas gingivalis $(\mathrm{Pg})$ revealed continuous germ reduction after 3 and 6 months (Figure 5c). However, no significance was found between the individual therapies for the different investigation periods. The same response was observed for Treponema denticola (Td), where, however, a significant influence of the laser treatments aPDT (1) and aPDT (2), with a common $p$-value of 0.011 , was demonstrated after 6 months. Similarly, this trend can also be seen for LILT, with a $p$-value of 0.11 (Figure $5 \mathrm{~d}$ ).

\section{Discussion}

The fundamental principles of both PDT and LILT have already been investigated in many in-vitro studies. Antimicrobial effects - also on periopathogens - are demonstrable under the given conditions [44]. However, LILT was also capable of inducing growth-accelerating effects [45].

As to the therapeutic measures, the selection of patients has been made randomly and hence also between smokers and non-smokers. With regard to these two groups, the results showed no noticeable differences. However, from the literature a relationship can be stated regarding the maintenance of residual pockets and smoking habits $[23,43,46,47]$. Consequently, more clinical studies especially adapted to this problem should be performed.

With respect to the germ reduction contradictory results were achieved to the literature. Using comparable laser settings and germ selection (Aa, Bf, Pg and Tf), MÜLlER CAMPANILE, et al. [43] could not prove germ reduction after 3 and 6 months.

In contrast to many in-vitro studies, the disease-inducing microorganisms in periodontitis are present not in a planktonic form, but as a biofilm in a morphologically complex pocket system. This situation creates special challenges for all decontaminating systems, including antibiotic treatment. Biofilm formation is far more resistant to all external stimuli than microorganisms in planktonic form [48]. For this reason, specific prerequisites have to be applied to clinical treatment systems in relation to the application technology and the selected parameters for the irradiation system and the photosensitizers used. In order to achieve relevant effects under clinical conditions, the data from basic research often have to be adjusted. Only a comparison of the various biofilm-inactivating systems makes it possible to decide whether and to what extent adjuvant antimicrobial systems can be meaningfully integrated into therapy. 

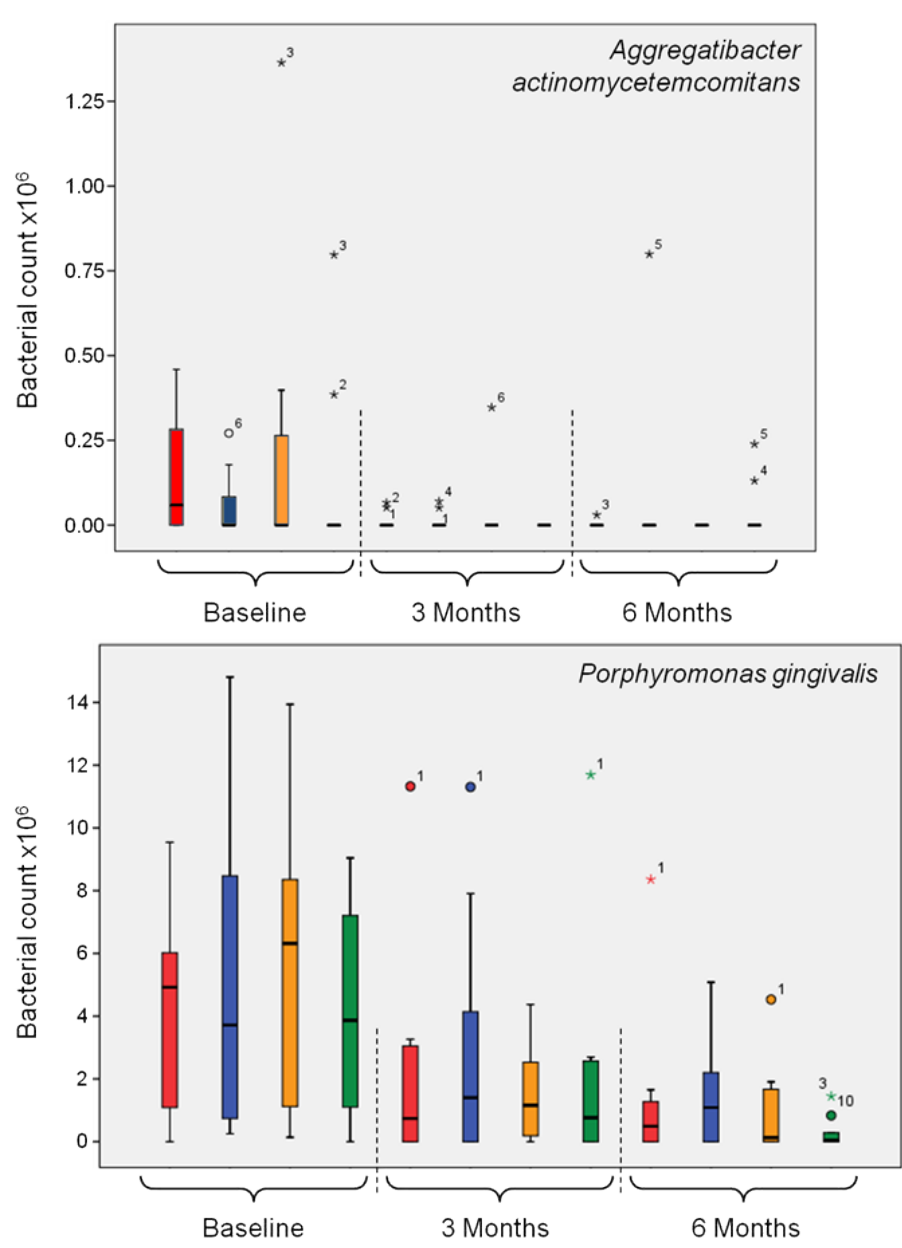

$\square$ Control

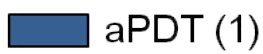

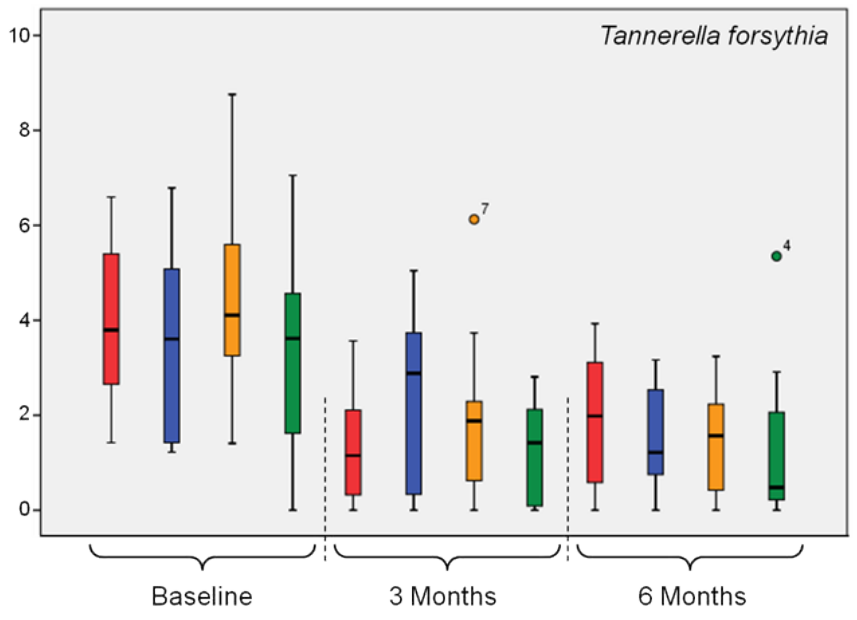

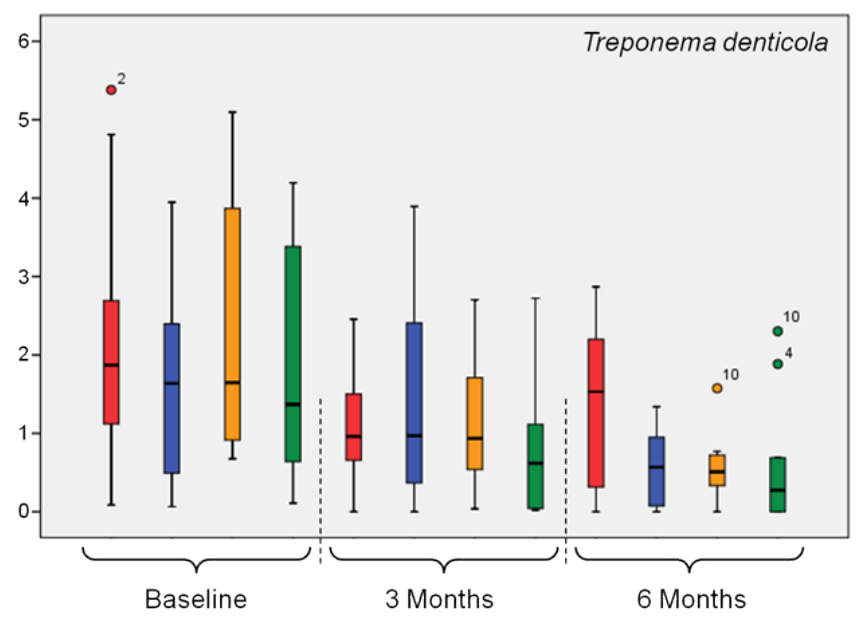

aPDT (2)

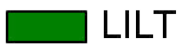

Figure 5. Individual depictions of the investigated germs Aa (top left), Bf (top right), Pg (below left) and Td (below right) at baseline as well as after 3 and 6 months, dependent of the different laser therapies applied

As in all systematic studies on periodontitis therapy, this investigation was likewise able to show that the gold standard in the therapy of periodontitis - systematic scaling and root planing, including corresponding hygiene instructions - substantially improves clinical parameters. Compared to the gold standard, the adjuvant systems examined were not capable of significantly influencing the probing depth and the microbial contamination of the gingival pockets studied. As in many other studies on aPDT, gingival pocket irradiation (aPDT (1)) again demonstrated a transient effect on BoP, which, as a clinical parameter, indicates a more favourable inflammation status [20]. This effect was not visible when using transgingival irradiation (aPDT (2)) or LILT.

This short-term effect of aPDT in this study, as also in many other clinical trials, is attributable to the fact that only a single application was performed. aPDT does not lead to "sustained-release effects", meaning that the effect is lost after a limited time and effects can no longer be detected. LANG [23] already established this some time ago. Consequently, the available findings confirm that more pronounced clinical results can only be expected if this adjuvant therapy is applied repeatedly in order to bring about long-term modification of the biofilm and thus achieve healing of the "gingival pocket" ecological niche [49]. Based on the fact that aPDT has so far not given rise to adverse effects under clinical conditions, there is nothing to stand in the way of this demand. Regarding transgingival irradiation of a gingival pocket, it must be noted that effects of absorption and scattering must be taken into consideration. In this respect, there are no systematic measurements to this day. The question thus arises as to whether the photosensitizer is sufficiently activated in this form of application.

Owing to the relatively small number of cases in this case series study, individual influences have a substantial impact, meaning that a larger patient population should be targeted in the context of further studies. However, in the spirit of a feasibility study, the study design used also proved successful under practical conditions.

\section{Conclusion}

In summary, it can be noted that, in the framework of this case series study, no adverse effects were observed when applying adjuvant photonic decontaminating procedures in the context of periodontitis therapy. Effects of one-time application were only detectable for aPDT (1). It appears necessary to repeat aPDT application at shorter intervals in order to be able to achieve long-term clinical effects $[23,50]$. In contrast to the administration of antibiotics, however, there is nothing to stand in the way of his approach. 


\section{Acknowledgements}

The authors would like to thank ORCOS Medical AG (Switzerland) and Bredent Medical GmbH \& Co. KG (Germany) for supplying the photodynamic laser systems used for this clinical investigation.

\section{Conflict of interest}

The authors declare that they have no conflict of interest

\section{Author disclosure statement}

No competing financial interests exist.

\section{References}

1. Johnell K, Fastbom J (2008) Multi-dose drug dispensing and inappropriate drug use: A nationwide register-based study of over 700,000 elderly. Scand J Prim Health Care 26: 86-91. [Crossref]

2. Quirynen M, Teughels W, De Soete M, van Steenberghe D (2002) Topical antiseptics and antibiotics in the initial therapy of chronic adult periodontitis: microbiological aspects. Periodontol 2000 28: 72-90. [Crossref]

3. Rossolini G, Mantengoli E (2008) Antimicrobial resistance in Europe and its potential impact on empirical therapy. Clin Microbiol Infect 14: 2-8. [Crossref]

4. Teles RP, Haffajee AD, Socransky SS (2006) Microbiological goals of periodontal therapy. Periodontol 2000 42: 180-218. [Crossref]

5. Haffajee AD, Cugini MA, Dibart S, Smith C, Kent R Jr., et al. (1997) The effect of SRP on the clinical and microbiological parameters of periodontal diseases. $J$ Clin Periodontol 24: 324-334. [Crossref]

6. Darby IB, Mooney J, Kinane DF (2001) Changes in subgingival microflora and humoral immune response following periodontal therapy. J Clin Periodontol 28: 796805. [Crossref]

7. Herrera D, Sanz M, Jepsen S, Needleman I, Roldán S (2002) A systematic review on the effect of systemic antimicrobials as an adjunct to scaling and root planing in periodontitis patients. J Clin Periodontol 29: 136-159. [Crossref]

8. Haffajee AD, Socransky SS, Gunsolley JC (2003) Systemic anti-infective periodontal therapy. A systematic review. Ann Periodontol 8: 115-181. [Crossref]

9. Mombelli A, Cionca N, Almaghlouth A (2011) Does adjunctive antimicrobial therapy reduce the perceived need for periodontal surgery? Periodontol 2000 55: 205-216. [Crossref]

10. EFSA (European Food Safety Authority), ECDC European Centre for Disease Prevention and Control (2016) The European Union summary report on antimicrobial resistance in zoonotic and indicator bacteria from humans, animals and food in 2014 EFSA Journal 14: 4380.

11. ARS (2019) (Antibiotic Resistance Surveillance.

12. Sharman WM, Allen CM, van Lier JE (1999) Photodynamic therapeutics: basic principles and clinical applications. Drug Discov Today 4: 507-517. [Crossref]

13. Dai T, Huang YY, Hamblin MR (2009) Photodynamic therapy for localized infections - state of the art. Photodiagnosis Photodyn Ther 6: 170-188. [Crossref]

14. Tavares A, Carvalho CM, Faustino MA, Neves MGPMS, Tomé JPC, et al. (2010) Antimicrobial photodynamic therapy: study of bacterial recovery viability and potential development of resistance after treatment. Mar Drugs 8: 91-105. [Crossref]

15. Maisch T, Hackbarth S, Regensburger J, Felgenträger A, Bäumler W, et al. (2011) Photodynamic inactivation of multi-resistant bacteria (PIB) - a new approach to trea superficial infections in the 21st century. J Dtsch Dermatol Ges 9: 360-366. [Crossref]

16. Dörtbudak O, Haas R, Bernhart T, Mailath-Pokorny G (2001) Lethal photosensitization for decontamination of implant surfaces in the treatment of peri-implantitis. Clin Oral Implants Res 12: 104-108. [Crossref]

17. Sculean A, Aoki A, Romanos G, Schwarz F, Miron RJ, et al. (2015) Is Photodynamic Therapy an Effective Treatment for Periodontal and Peri-Implant Infections? Dent Clin North Am 59: 831-858. [Crossref]

18. Al Habashneh R, Asa'ad FA, Khader Y (2015) Photodynamic therapy in periodontal and peri-implant diseases. Quintessence Int 46: 677-690. [Crossref]

19. De Oliveira RR, Schwartz-Filho HO, Novaes AB Jr., Taba M Jr. (2007) Antimicrobial photodynamic therapy in the non-surgical treatment of aggressive periodontitis: a preliminary randomized controlled clinical study. J Periodontol 78: 965-973. [Crossref]
20. Braun A, Dehn C, Krause F, Jepsen S (2008) Short-term clinical effects of adjunctive antimicrobial photodynamic therapy in periodontal treatment: a randomized clinical trial. J Clin Periodontol 35: 877-884. [Crossref]

21. Christodoulides N, Nikolidakis D, Chondros P, Becker J, Schwarz F, et al. (2008) Photodynamic therapy as an adjunct to non-surgical periodontal treatment: a randomized, controlled clinical trial. J Periodontol 79: 1638-1644. [Crossref]

22. de Oliveira RR, Schwartz-Filho HO, Novaes AB, Garlet GP, de Souza RF, et al. (2009) Antimicrobial photodynamic therapy in the non-surgical treatment of aggressive periodontitis: cytokine profile in gingival crevicular fluid, preliminary results. $J$ Periodontol 80: 98-105. [Crossref]

23. Lulic M, Leiggener Görög I, Salvi GE, Ramseier CA, Mattheos N, et al. (2009) One-year outcomes of repeated adjunctive photodynamic therapy during periodontal maintenance: a proof-of-principle randomized-controlled clinical trial. $J$ Clin Periodontol 36: 661-666. [Crossref]

24. Novaes AB Jr, Schwartz-Filho HO, de Oliveira RR, Feres M, Sato S, et al. (2012) Antimicrobial photodynamic therapy in the non-surgical treatment of aggressive periodontitis: microbiological profile. Lasers Med Sci 27: 389-395. [Crossref]

25. Sigusch BW, Engelbrecht M, Völpel A, Holletschke A, Pfister W, et al. (2010) Fullmouth antimicrobial photodynamic therapy (PDT) in Fusobacterium nucleatuminfected periodontitis patients. J Periodontol 81: 975-981. [Crossref]

26. Pfitzner A, Sigusch BW, Albrecht V, Glockmann E (2004) Killing of periodontopathogenic bacteria by photodynamic therapy. J Periodontol 75: 1343-1349. [Crossref]

27. Dobson J, Wilson M (1992) Sensitization of oral bacteria in biofilms to killing by light from a low-power laser. Arch Oral Biol 37: 883-887. [Crossref]

28. Sgolastra F, Petrucci A, Gatto R, Marzo G, Monaco A (2013) Photodynamic therapy in treatment of chronic periodontitis: a systematic review and meta-analysis. Laser Med Sci 28: 669-682. [Crossref]

29. Atieh MA (2010) Photodynamic Therapy as an adjunctive treatment for chronic periodontitis: a meta-analysis. Lasers Med Sci 25: 605-613. [Crossref]

30. Malik R, Manocha A, Suresh DK (2010) Photodynamic therapy - a strategic review. Indian J Dent Res 21: 285-291. [Crossref]

31. Kaskos H, Al-Hassan A (2011) Effect of low-level laser therapy on intra oral wounding. Al-Rafidain Dent J 11: 105-112

32. Hakkinen L, Uitto VJ, Larjava H (2000) Cell biology of gingival wound healing Periodontol 2000 24: 127-152. [Crossref]

33. Hamblin M, Demidova T (2006) Mechanism of low-level light therapy. In: Hamblin MR, Waynant RW, Anders J, Eds., Mechanisms for low-light therapy, Proceedings SPIE 6140: 614001.

34. Catstro GL, Gallas M, Nunez IR, Borrajo JLL, Varela LG (2006) Histologica evaluation of the use of diode laser as an adjunct to traditional periodontal treatment. Photomed Laser Surg 24: 64-68. [Crossref]

35. Kreisler M, Christoffers AB, Al-Haj H, Willershausen B, d'Hoedt B (2002) Low level 809 -nm diode-laser-induced in vitro stimulation of the proliferation of human gingival fibroblasts. Laser Surg Med 30: 365-369. [Crossref]

36. Schwarz F, Aoki A, Sculean A, Becker J (2009) The impact of laser application on periodontal and peri-implant wound healing. Periodontol 2000 51: 79-108. [Crossref]

37. Choi EJ, Yim JK, Koo KT, Seol YJ, Lee YM, et al. (2010) Biological effects of a semiconductor diode laser on human periodontal ligaments fibroblasts. $J$ Periodontal Implant Sci 40: 105-110. [Crossref]

38. Basso FG, Pansani TN, Turrioni AP, Bagnato VS, Helbling J, et al. (2012) In vitro wound healing improvement by low-level laser therapy application in cultured gingival fibroblasts. Int J Dent 2012: 719452. [Crossref]

39. Khadra M, Lyngstadaas SP, Haanaes HR, Mustafa K (2005) Effect of laser therapy on attachment, proliferation and differentiation of human osteoblast-like cells cultured on titanium implant material. Biomaterials 26: 3503-3509. [Crossref]

40. Pyo SJ, Song WW, Kim IR, Park BS, Kim CH, et al. (2013) Low-level laser therapy induces the expressions of BMP-2, osteocalcin and TGF- $\beta 1$ in hypoxic-cultured human osteoblasts. Lasers Med Sci 28: 543-550. [Crossref]

41. Saafan A, El-Nahass H, Nasr AS, Radwan R (2013) Effect of low-power diode laser $810 \mathrm{~nm}$ on TGF- $\beta 1$ level in GCF in aggressive periodontitis. $J$ Dent Lasers 7: 59-65.

42. Aykol G, Baser U, Maden I, Kazak Z, Onan U, et al. (2011) The effect of low-leve laser therapy as an adjunct to non-surgical periodontal treatment. J Periodontol 82 : 481-488. [Crossref] 
43. Muller Campanile VS, Giannopoulou C, Campanile G, Cancela JA, Mombelli A (2015) Single or repeated antimicrobial photodynamic therapy as adjunct to ultrasonic debridement in residual periodontal pockets: clinical, microbiological, and local biological effects. Lasers Med Sci 30: 27-34. [Crossref]

44. Cieplik F, Tabenski L, Buchalla W, Maisch T (2014) Antimicrobial photodynamic therapy for inactivation of biofilms formed by oral key pathogens. Front Microbiol 5 405. [Crossref]

45. Tiphlova O, Karu T (1991) Action of low-intensity laser radiation on Escherichia coli. Crit Rev Biomed Eng 18: 387-412. [Crossref]

46. Rieder C, Joss A, Lang NP (2004) Influence of compliance and smoking habits on the outcomes of supportive periodontal therapy (SPT) in a private practice. Oral Health Prev Dent 2: 89-94. [Crossref]
47. Matuliene G, Pjetursson BE, Salvi GE, Schmidlin K, Bragger U, et al. (2008) Influence of residual pockets on progression of periodontitis and tooth loss: results after 11 years of maintenance. J Clin Periodontol 35: 685-695. [Crossref]

48. Olsen I (2015) Biofilm-specific antibiotic tolerance and resistance. Eur J Clin Microbiol Infect Dis 34: 877-886. [Crossref]

49. Franco TPM, Dos Santos APP, Canabarro A (2019) The effects of repeated applications of antimicrobial photodynamic therapy in the treatment of residual periodontal pockets a systematic review. Lasers Med Sci 34: 855-863. [Crossref]

50. Petelin M, Perkič K, Seme K, Gašpirc B (2015) Effect of repeated adjunctive antimicrobial photodynamic therapy on subgingival periodontal pathogens in the treatment of chronic periodontitis. Lasers Med Sci 30: 1647-1656. [Crossref]

Copyright: @2019 Vock M. This is an open-access article distributed under the terms of the Creative Commons Attribution License, which permits unrestricted use, distribution, and reproduction in any medium, provided the original author and source are credited. 